\title{
Didymella corylicola sp. nov., a new fungus associated with hazelnut fruit development in Italy
}

\author{
Marzia Scarpari ${ }^{1}$ - Salvatore Vitale ${ }^{1}$ - Giuseppe Di Giambattista ${ }^{1}$ - Laura Luongo ${ }^{1}$ - Tommaso De Gregorio ${ }^{2}$. \\ Giulio Schreiber $^{3} \cdot$ Mariangela Petrucci $^{3} \cdot$ Alessandra Belisario $^{1} \cdot$ Hermann Voglmayr ${ }^{4,5}$ (I)
}

Received: 17 December 2019 / Revised: 20 January 2020 / Accepted: 21 January 2020

(C) The Author(s) 2020

\begin{abstract}
A new fungal species constantly associated with hazelnut (Corylus avellana) fructification starting from its primordia is described. The fungus is associated with hazelnut fruit during all their developmental stages, being consistently more present in spring (March-June). A 4-year survey has been conducted, from young fruit formation to full kernel maturity including also the post-harvest phase, to collect fungi associated with damaged/discoloured kernels. A collection of 60 isolates of a new species has been obtained in this study, which is here described as Didymella corylicola sp. nov. Multi-locus phylogenies based on four genomic loci (nuITS and LSU rDNA, RPB2 and TUB2) in combination with morphological data confirmed the fungus to represent a new species of Didymella (Didymellaceae). The occurrence of D. corylicola sp. nov. might have an impact on the quality of hazelnut production by contributing to kernel defects.
\end{abstract}

Keywords Corylus avellana $\cdot$ Kernel defects $\cdot$ Nut disease $\cdot$ Phoma $\cdot$ Pleosporales $\cdot 1$ new species

\section{Introduction}

Hazelnut (Corylus avellana L.) is native to Europe and Western Asia where it is widely distributed (Olsen 2013; Enescu et al. 2016). The main hazelnut producing countries are Turkey, Italy and the USA. Turkey produces over $60 \%$ of the world total, followed by Italy, Azerbaijan and the United

Section Editor: Roland Kirschner

Hermann Voglmayr

hermann.voglmayr@univie.ac.at

1 Centro di ricerca per la Difesa e la Certificazione (CREA-DC), Consiglio per la Ricerca in Agricoltura e l'analisi dell'economia agraria, Rome, Italy

2 Ferrero Hazelnuts Company, Division of Ferrero Trading Luxembourg, 16, Route de Trèves,

L-2633 Senningerberg, Luxembourg

3 SAGEA srl, Castagnito, Italy

4 Institute of Forest Entomology, Forest Pathology and Forest Protection, Department of Forest and Soil Sciences,

BOKU-University of Natural Resources and Life Sciences, Franz

Schwackhöfer Haus, Peter-Jordan-Straße 82/I, 1190 Vienna, Austria

5 Division of Systematic and Evolutionary Botany, Department of Botany and Biodiversity Research, University of Vienna, Rennweg 14, 1030 Wien, Austria
States (FAOSTAT; data for 2017 retrieved from http://www. fao.org/faostat/en/\#data/QC). Commercial hazelnut orchards have expanded significantly in the last years due to an increasing demand for direct consumption of fruit as well as often in combination with chocolate. Nearly $90 \%$ of the harvested yield is destined to processing companies, whereas fresh consumption represents the residual 10\%. Hazelnut cultivation is dispersed all over Italy, from north to south, with main production located in Piedmont (26\%), Latium (32\%), Campania (28\%) and Sicily (9\%) regions (ISTAT, http://dati.istat.it/). These percentages just give an indication since production may vary from year to year. Hazelnut is characterized by good rusticity which makes it an adaptable fruit tree species compared to other nut species such as almond, walnut and pistachio. Nevertheless, it is affected by several diseases and fungal pathogens which can be particularly harmful in altering the kernel and consequently reducing harvest quality and yield. Hazelnut represents a high value product suffering kernel defects which might be climate dependent, inducing production fluctuations. In Piedmont and in Campania, gleosporiosis (purple necrotic spots on female flowers, petioles, nut bracts and husk), caused by Elsinoe coryli (syn. Sphaceloma coryli), has been reported (Minutolo et al. 2016), while in central Italy (Latium, Viterbo province) and in Campania, Alternaria spp., Colletotrichum spp., Fusarium spp. and Diaporthe spp. have 
also been isolated (Librandi et al. 2006). From the year 2000 onwards, special attention has been given to identify the causal agent of hazelnut fruit drop, known as nut grey necrosis (NGN) disease, which was identified as Fusarium lateritium (Vitale et al. 2011). In this extensive survey, an unknown fungus with typical deeply red-pigmented colonies was isolated in every phenological phase, particularly in the early stages of hazelnut fruit formation. This fungus was also isolated in the surveys from 2016 onwards, which were addressed to identify the fungi associated with kernel damage/ discoloration and the potential causal agents of kernel defects.

The aims of this study were to provide morphological, taxonomic and phylogenetic data for the red-pigmented fungus which proved to be an undescribed species of the genus Didymella. Experimental evidence on its relation with hazelnut kernel defects is given.

\section{Materials and methods}

\section{Field surveys and isolations}

In past years, numerous surveys were carried out, mainly in Latium region, on the causal agent of the nut grey necrosis (NGN) disease, which caused heavy losses for about 10 years, starting from its outbreak in 2000 (Vitale et al. 2011). More recently, surveys of a total of 9 hazelnut orchards were conducted from 2016 to 2019 in Campania, as well as in 7 hazelnut orchards located in Piedmont. Except for 2016, in which the survey started at fruit yield, sampling started from the end of March onwards, considering several phenological stages, namely, bud break/initial fruit formation (March-April), nut development (May-June), embryo and kernel development (late June-July), ripening nuts-harvest phase (AugustSeptember), and post-harvest sampling (SeptemberOctober). About 300 fruits were sampled per orchard. Samples were subjected to surface disinfection in $10 \%$ sodium hypochlorite for $60 \mathrm{~s}$, rinsed in sterile water for $60 \mathrm{~s}$, and dried on sterile filter paper in a laminar flow. Tissue fragments were placed onto potato dextrose agar (PDA) Petri dishes at $25^{\circ} \mathrm{C}$ in the dark, and daily observed for mycelial growth. Numerous red-pigmented cultures were obtained, and singleconidial isolations were performed with conidia collected from pycnidia produced on those cultures within 1 month of incubation at room temperature under daylight. More than 60 single-spore isolates were obtained from symptomatic tissue isolation. Amongst these, 10 isolates representative of the three main colony morphologies were characterized by molecular data and phylogenetic analyses (Table 1), and the three isolates CREADC-F2281, CREADC-F2402 and CREADCF2403 were subjected to detailed morphological, taxonomic, phylogenetic and pathogenic studies.

\section{Morphological characterization}

For culture characteristics, colonies were grown on $2 \%$ (w/v) malt extract agar (MEA, VWR), potato dextrose agar (PDA, Sigma-Aldrich), corn meal agar (CMA, Sigma-Aldrich) supplemented with $2 \% \mathrm{w} / \mathrm{v}$ dextrose (CMD), oatmeal agar (OA, Sigma-Aldrich) and hazelnut extract agar (HEA; $25 \mathrm{~g} / 1$ fresh chopped hazel twigs, autoclaved in $2 \%$ agar). Colony diameters were measured after 7 days, and colony morphologies were determined after 14 days of incubation at room temperature $\left(22{ }^{\circ} \mathrm{C}\right)$ and daylight. To promote pycnidial formation, cultures were grown on HEA and hazel twig agar (HTA; autoclaved split hazel twigs placed on $2 \%$ agar plates, shortly before solidification). The isolates used in this study are maintained in the culture collection of the CREA-DC (ex CREA-PAV). The ex-holotype isolate (CREADC-F2403) of the new hazelnut pathogen was deposited at the Westerdijk Fungal Biodiversity Institute (CBS), Utrecht, The Netherlands, and the holotype specimen in the fungarium of the Department of Botany and Biodiversity Research, University of Vienna (WU).

Microscopic observations were made in tap water except where noted in the figure legend. Sections of $8 \mu \mathrm{m}$ thickness of pycnidia were prepared with a Leica FrigoCut 2700 freezing microtome. Methods of microscopy included stereomicroscopy using a Nikon SMZ 1500 equipped with a Nikon DS-U2 digital camera, and Nomarski differential interference contrast (DIC) using a Zeiss Axio Imager.A1 compound microscope equipped with a Zeiss Axiocam 506 colour digital camera. Images and data were gathered using the NIS-Elements D v. 3.22.15 or Zeiss ZEN Blue Edition software packages. Measurements are reported as maxima and minima in parentheses and the range representing the mean plus and minus the standard deviation of a number of measurements given in parentheses.

\section{Temperature-growth relationships}

For investigations of temperature-growth relationships of the new hazelnut fungus, the ex-holotype isolate CREADC-F2403, and the isolates CREADC-F2281 and CREADC-F2402 were used. Agar plugs ( $5 \mathrm{~mm}$ diameter) were taken from the edge of actively growing cultures on PDA and transferred onto the centre of 9-cm PDA Petri dishes. Three replicate plates were incubated at 5, 10, 15, $20,25,30$ and $35{ }^{\circ} \mathrm{C}$ in the dark and measurements were taken after 7 days at right angles along two lines intersecting the centre of the inoculum and the mean growth rates plus and minus the standard deviation $( \pm$ $\mathrm{SD})$ were calculated. 
Table 1 Isolates and accession numbers of sequences used in the phylogenetic analyses. Isolates and sequences in bold were obtained in the present study

\begin{tabular}{|c|c|c|c|c|c|}
\hline \multirow[t]{2}{*}{ Species } & \multirow[t]{2}{*}{ Strain number ${ }^{1}$} & \multicolumn{4}{|c|}{ GenBank accession numbers ${ }^{2}$} \\
\hline & & LSU & ITS & $R P B 2$ & $T U B 2$ \\
\hline Didymella acetosellae & CBS 179.97 & GU238034 & GU237793 & KP330415 & GU237575 \\
\hline \multirow[t]{2}{*}{ D. aeria } & LC 8120 & KY742052 & KY742206 & KY742138 & KY742294 \\
\hline & CGMCC 3.18353 & KY742051 & KY742205 & KY742137 & KY742293 \\
\hline D. aliena & CBS 379.93; PD 82/945 & GU238037 & GU237851 & KP330416 & GU237578 \\
\hline \multirow[t]{2}{*}{ D. americana } & CBS $185.85 ;$ PD 80/1191 & GU237990 & FJ426972 & KT389594 & FJ427088 \\
\hline & CBS 568.97; ATCC 44494; PD 94/1544 & GU237991 & FJ426974 & - & FJ427090 \\
\hline \multirow[t]{4}{*}{ D. anserina } & CBS 253.80 & KT389715 & KT389498 & KT389595 & KT389795 \\
\hline & CBS 285.29 & KT389716 & KT389499 & - & KT389796 \\
\hline & CBS 360.84 & GU237993 & GU237839 & KT389596 & GU237551 \\
\hline & CBS 397.65 & KT389717 & KT389500 & KT389597 & KT389797 \\
\hline \multirow[t]{2}{*}{ D. aquatica } & CGMCC 3.18349 & KY742055 & KY742209 & KY742140 & KY742297 \\
\hline & LC 5555 & KY742056 & KY742210 & KY742141 & KY742298 \\
\hline D. arachidicola & CBS 333.75; ATCC 28333; IMI 386092; PREM 44889 & GU237996 & GU237833 & KT389598 & GU237554 \\
\hline D. aurea & CBS 269.93; PD 78/1087 & GU237999 & GU237818 & KT389599 & GU237557 \\
\hline \multirow[t]{2}{*}{ D. bellidis } & CBS 714.85; PD 74/265 & GU238046 & GU237904 & KP330417 & GU237586 \\
\hline & PD 94/886 & GU238047 & GU237923 & - & GU237587 \\
\hline D. boeremae & CBS 109942; PD 84/402 & GU238048 & FJ426982 & KT389600 & FJ427097 \\
\hline D. brunneospora & CBS 115.58; DSM 62044 & KT389723 & KT389505 & KT389625 & KT389802 \\
\hline \multirow[t]{2}{*}{ D. calidophila } & CBS 448.83 & GU238052 & FJ427059 & - & FJ427168 \\
\hline & PD 84/109 & GU238053 & FJ427060 & - & FJ427169 \\
\hline D. chenopodii & CBS 128.93; PD 79/140 & GU238055 & GU237775 & KT389602 & GU237591 \\
\hline \multirow[t]{2}{*}{ D. chloroguttulata } & CGMCC 3.18351 & KY742057 & KY742211 & KY742142 & KY742299 \\
\hline & LC 8122 & KY742058 & KY742212 & KY742143 & KY742300 \\
\hline D. coffeae-arabicae & CBS 123380; PD 84/1013 & GU238005 & FJ426993 & KT389603 & FJ427104 \\
\hline \multirow[t]{11}{*}{ D. corylicola } & CREADC-F2281 & MN954299 & MN954288 & MN958321 & MN958331 \\
\hline & CREADC-F2402 & MN954300 & MN954289 & MN958322 & MN958332 \\
\hline & CBS 146357; CREADC-F2403 & MN954301 & MN954290 & MN958323 & MN958333 \\
\hline & CREADC-F2404 & MN954302 $^{3}$ & MN954291 $^{3}$ & - & - \\
\hline & CREADC-F2405 & MN954303 & MN954292 & MN958324 & MN958334 \\
\hline & CREADC-F2406 & MN954304 & MN954293 & MN958325 & MN958335 \\
\hline & CREADC-F2407 & MN954305 & MN954294 & MN958326 & MN958336 \\
\hline & CREADC-F2408 & MN954306 & MN954295 & MN958327 & MN958337 \\
\hline & CREADC-F2409 & MN954307 & MN954296 & MN958328 & MN958338 \\
\hline & CREADC-F2410 & MN954308 & MN954297 & MN958329 & MN958339 \\
\hline & CREADC-F2411 & MN954309 & MN954298 & MN958330 & MN958340 \\
\hline \multirow[t]{2}{*}{ D. curtisii } & CBS 251.92; PD 86/1145 & GU238013 & FJ427038 & - & FJ427148 \\
\hline & PD 92/1460 & GU238012 & FJ427041 & KT389604 & FJ427151 \\
\hline D. dactylidis & CBS 124513; PD 73/1414 & GU238061 & GU237766 & - & GU237599 \\
\hline D. dimorpha & CBS 346.82 & GU238068 & GU237835 & - & GU237606 \\
\hline \multirow[t]{2}{*}{ D. ellipsoidea } & CGMCC 3.18350 & KY742060 & KY742214 & KY742145 & KY742302 \\
\hline & LC 8123 & KY742061 & KY742215 & KY742146 & KY742303 \\
\hline D. eucalyptica & CBS 377.91; PD 79/210 & GU238007 & GU237846 & KT389605 & GU237562 \\
\hline D. exigua & CBS 183.55 & EU754155 & GU237794 & EU874850 & GU237525 \\
\hline D. gardeniae & CBS 626.68; IMI 108771 & GQ387595 & FJ427003 & KT389606 & FJ427114 \\
\hline \multirow[t]{2}{*}{ D. glomerata } & CBS 133.72 & KT389718 & FJ427004 & - & FJ427115 \\
\hline & CBS 528.66; PD 63/590 & EU754184 & FJ427013 & GU371781 & FJ427124 \\
\hline
\end{tabular}


Table 1 (continued)

\begin{tabular}{|c|c|c|c|c|c|}
\hline \multirow[t]{2}{*}{ Species } & \multirow[t]{2}{*}{ Strain number ${ }^{1}$} & \multicolumn{4}{|c|}{ GenBank accession numbers ${ }^{2}$} \\
\hline & & LSU & ITS & $R P B 2$ & $T U B 2$ \\
\hline D. heteroderae & CBS 109.92; PD 73/1405 & GU238002 & FJ426983 & KT389601 & FJ427098 \\
\hline \multirow[t]{2}{*}{ D. ilicicola } & CGMCC 3.18355 & KY742065 & KY742219 & KY742150 & KY742307 \\
\hline & LC 8127 & KY742066 & KY742220 & KY742151 & KY742308 \\
\hline \multirow[t]{2}{*}{ D. infuscatispora } & CGMCC 3.18356 & KY742067 & KY742221 & KY742152 & KY742309 \\
\hline & LC 8129 & KY742068 & KY742222 & - & KY742310 \\
\hline \multirow[t]{3}{*}{ D. keratinophila } & CBS 143032; UTHSC:DI16-200; FMR 13690 & LT592901 & LN907343 & LT593039 & LT592970 \\
\hline & UTHSC:DI16-228; FMR 13718 & LT592915 & LN907371 & LT593053 & LT592984 \\
\hline & UTHSC:DI16-282; FMR 13774 & LT592938 & LN907425 & LT593077 & LT593007 \\
\hline D. lethalis & CBS 103.25 & GU238010 & GU237729 & KT389607 & GU237564 \\
\hline D. longicolla & CBS 124514; PD 80/1189 & GU238095 & GU237767 & - & GU237622 \\
\hline \multirow[t]{2}{*}{ D. macrophylla } & CGMCC 3.18357 & KY742070 & KY742224 & KY742154 & KY742312 \\
\hline & LC 8132 & KY742071 & KY742225 & KY742155 & KY742313 \\
\hline \multirow[t]{4}{*}{ D. macrostoma } & CBS 482.95 & GU238099 & GU237869 & KT389609 & GU237626 \\
\hline & CBS 529.66; PD 66/521 & GU238098 & GU237885 & - & GU237625 \\
\hline & CBS 223.69 & GU238096 & GU237801 & KT389608 & GU237623 \\
\hline & CBS 247.38 & КТ389719 & KT389501 & - & KT389798 \\
\hline D. maydis & CBS 588.69 & EU754192 & FJ427086 & GU371782 & FJ427190 \\
\hline D. microchlamydospora & CBS 105.95 & GU238104 & FJ427028 & KP330424 & FJ427138 \\
\hline \multirow[t]{2}{*}{ D. molleriana } & CBS 229.79; LEV 7660 & GU238067 & GU237802 & KP330418 & GU237605 \\
\hline & CBS 109179; PD 90/835-1 & GU238066 & GU237744 & - & GU237604 \\
\hline D. musae & CBS 463.69 & GU238011 & FJ427026 & LT623248 & FJ427136 \\
\hline D. negriana & CBS 358.71 & GU238116 & GU237838 & KT389610 & GU237635 \\
\hline \multirow[t]{2}{*}{ D. nigricans } & CBS 444.81; PDDCC 6546 & GU238000 & GU237867 & - & GU237558 \\
\hline & PD 77/919 & GU238001 & GU237915 & KT389611 & GU237559 \\
\hline \multirow[t]{2}{*}{ D. ocimicola } & CGMCC 3.18358 & KY742078 & KY742232 & - & KY742320 \\
\hline & LC 8138 & KY742079 & KY742233 & - & KY742321 \\
\hline D. pedeiae & CBS 124517; PD 92/612A & GU238127 & GU237770 & KT389612 & GU237642 \\
\hline \multirow[t]{2}{*}{ D. pinodella } & CBS 318.90; PD 81/729 & GU238016 & FJ427051 & - & FJ427161 \\
\hline & CBS 531.66 & GU238017 & FJ427052 & KT389613 & FJ427162 \\
\hline D. pinodes & CBS 525.77 & GU238023 & GU237883 & KT389614 & GU237572 \\
\hline \multirow[t]{4}{*}{ D. pomorum } & CBS 285.76; ATCC 26241; IMI 176742; VKM F-1843 & GU238025 & FJ427053 & KT389615 & FJ427163 \\
\hline & CBS 388.80 & GU238027 & FJ427055 & KT389617 & FJ427165 \\
\hline & CBS 539.66; ATCC 16791; IMI 122266; PD 64/914 & GU238028 & FJ427056 & KT389618 & FJ427166 \\
\hline & CBS 354.52 & KT389720 & KT389502 & KT389616 & KT389799 \\
\hline \multirow[t]{4}{*}{ D. protuberans } & CBS 132.96; PD 93/853 & GU237989 & GU237778 & - & GU237550 \\
\hline & CBS 377.93; PD 80/976 & GU238014 & GU237847 & KT389619 & GU237565 \\
\hline & CBS 391.93; PD 80/87 & GU238015 & GU237858 & KT389621 & GU237566 \\
\hline & CBS 381.96; PD 71/706 & GU238029 & GU237853 & KT389620 & GU237574 \\
\hline D. pteridis & CBS 379.96 & КТ389722 & KT389504 & KT389624 & KT389801 \\
\hline D. rhei & CBS 109177; LEV 15165; PD 2000/9941 & GU238139 & GU237743 & KP330428 & GU237653 \\
\hline D. rosea & BRIP 50788 & KT287003 & KT338640 & - & KT286945 \\
\hline D. rumicicola & CBS 683.79; LEV 15094 & KT389721 & KT389503 & KT389622 & KT389800 \\
\hline D. sancta & CBS 281.83 & GU238030 & FJ427063 & KT389623 & FJ427170 \\
\hline \multirow[t]{2}{*}{ D. segeticola } & CGMCC 3.17489 & KP330443 & KP330455 & KP330414 & KP330399 \\
\hline & CGMCC 3.17498 & KP330442 & KP330454 & KP330413 & KP330398 \\
\hline D. senecionicola & CBS 160.78; LEV 11451 & GU238143 & GU237787 & - & GU237657 \\
\hline D. sinensis & LC 8142 & KY742087 & KY742241 & KY742166 & KY742329 \\
\hline
\end{tabular}


Table 1 (continued)

\begin{tabular}{|c|c|c|c|c|c|}
\hline \multirow[t]{2}{*}{ Species } & \multirow[t]{2}{*}{ Strain number ${ }^{1}$} & \multicolumn{4}{|c|}{ GenBank accession numbers $^{2}$} \\
\hline & & LSU & ITS & $R P B 2$ & $T U B 2$ \\
\hline & LC 8143 & KY742088 & KY742242 & KY742167 & KY742330 \\
\hline D. subglomerata & CBS 110.92; PD 76/1010 & GU238032 & FJ427080 & KT389626 & FJ427186 \\
\hline \multirow[t]{2}{*}{ D. subherbarum } & CBS 249.92; PD 78/1088 & GU238144 & GU237808 & - & GU237658 \\
\hline & CBS 250.92; DAOM 171914; PD 92/371 & GU238145 & GU237809 & - & GU237659 \\
\hline \multirow[t]{2}{*}{ D. suiyangensis } & CGMCC 3.18352 & KY742089 & KY742243 & KY742168 & KY742331 \\
\hline & LC 8144 & KY742090 & KY742244 & KY742169 & KY742332 \\
\hline D. tanaceti & BRIP 50785 & KT287022 & KT338641 & - & KT286974 \\
\hline D. viburnicola & CBS 523.73; PD 69/800 & GU238155 & GU237879 & KP330430 & GU237667 \\
\hline Macroventuria anomochaeta & CBS 525.71 & GU237984 & GU237881 & GU456346 & GU237544 \\
\hline M. wentii & CBS 526.71 & GU237986 & GU237884 & KT389642 & GU237546 \\
\hline \multirow[t]{2}{*}{ Paraboeremia adianticola } & CBS 187.83; PD 82/128 & GU238035 & GU237796 & KP330401 & GU237576 \\
\hline & CBS 260.92; PD 86/1103 & KT389752 & КT389534 & - & KT389832 \\
\hline P. putaminum & CBS 130.69; CECT 20054; IMI 331916 & GU238138 & GU237777 & LT623254 & GU237652 \\
\hline P. selaginellae & CBS 122.93; PD 77/1049 & GU238142 & GU237762 & LT623255 & GU237656 \\
\hline
\end{tabular}

${ }^{1}$ ATCC, American Type Culture Collection, Virginia, USA; BRIP, Queensland Plant Pathology Herbarium, Brisbane, Australia; CBS: Centraalbureau voor Schimmelcultures, Utrecht, The Netherlands; $C E C T$, Colección Española de Cultivos Tipo, Valencia University, Spain; $C G M C C$, China General Microbiological Culture Collection, Beijing, China; $C R E A D C$, Consiglio per la Ricerca in Agricoltura e l'analisi dell'economia agraria, Centro di ricerca per la Difesa e la Certificazione, Roma, Italy; DAOM, Canadian Collection of Fungal Cultures, Ottawa, Canada; DSM, Deutsche Sammlung von Mikroorganismen und Zellkulturen GmbH, Braunschweig, Germany; IMI, International Mycological Institute, CABI-Bioscience, Egham, Bakeham Lane, UK; $L C$, L. Cai personal collection housed at the Chinese Academy of Sciences (CAS), China; LEV, Plant Health and Diagnostic Station, Auckland, New Zealand; $P D$, Plant Protection Service, Wageningen, the Netherlands; $P D D C C$, Plant Diseases Division Culture Collection, Auckland, New Zealand; PREM, National Collection of Fungi: Culture Collection, Pretoria, South Africa; UTHSC, Fungus Testing Laboratory at the University of Texas Health Science Center, San Antonio, Texas, USA; VKM, All-Russian Collection of Microorganisms, Pushchino, Russia

${ }^{2} I T S$, internal transcribed spacer regions 1 and 2 including 5.8S nrDNA gene; $L S U, 28 \mathrm{~S}$ large subunit of the nrRNA gene; RPB2, RNA polymerase II second largest subunit; TUB2, ß-tubulin

${ }^{3}$ ITS-LSU sequences not included in the phylogenetic analyses, as they were identical to other accessions of $D$. corylicola sequenced

\section{DNA extraction, PCR amplification and sequencing}

The extraction of genomic DNA from pure cultures was performed as reported in previous studies (Voglmayr and Jaklitsch 2011; Vitale et al. 2018) by using the DNeasy Plant Mini Kit (QIAgen GmbH, Hilden, Germany) or the Wizard Genomic DNA Purification Kit (Promega Corporation, WI, USA). For the ex-holotype strain of the new species, the complete internal transcribed spacer region (ITS1-5.8S-ITS2) and a ca. $0.9 \mathrm{~kb}$ fragment of the large subunit nuclear ribosomal DNA (nLSU rDNA) were amplified and sequenced as a single fragment with primers V9G (de Hoog and Gerrits van den Ende 1998) and LR5 (Vilgalys and Hester 1990); the complete ITS region of the other strains was amplified with primers ITS5 and ITS4 (White et al. 1990); the RNA polymerase II subunit 2 (RPB2) gene was amplified with primers fRPB2-5F2 and fRPB2-7cR (Liu et al. 1999, Sung et al. 2007) or dRPB2-5f and dRPB2-7r (Voglmayr et al. 2016); and the beta-tubulin (TUB2) gene with primer pairs T1 and T22 or TUB2Fd and TUB4Rd (O'Donnell and Cigelnik 1997; Aveskamp et al. 2009). The PCR product was purified using an enzymatic PCR cleanup (Werle et al. 1994) as described in Voglmayr and Jaklitsch (2008). DNA was cycle- sequenced using the ABI PRISM Big Dye Terminator Cycle Sequencing Ready Reaction Kit v. 3.1 (Applied Biosystems, Warrington, UK) with the same primers as in PCR; in addition, primers ITS4, LR2R-A (Voglmayr et al. 2012) and LR3 (Vilgalys and Hester 1990) were used for the ITS-LSU fragment. Sequencing was performed on an automated DNA sequencer (3730xl Genetic Analyser, Applied Biosystems).

\section{Phylogenetic analyses}

The newly generated sequences were aligned with selected sequences of Chen et al. (2017) and complemented with a few recent additions from GenBank. The GenBank accession numbers of sequences used in the analyses are given in Table 1. A combined matrix of the three loci (partial nuITS-LSU rDNA, RPB2 and TUB2) was produced for phylogenetic analyses, with two species of Macroventuria (M. anomochaeta, $M$. wentii) and three species of Paraboeremia (P. adianticola, P. putaminum and $P$. selaginellae) added as the outgroup taxa according to the results of the phylogenetic analyses of Chen et al. (2017). Sequence alignments were produced with the server 
version of MAFFT (http://mafft.cbrc.jp/ alignment/server/) , checked and refined using BioEdit v. 7.2.6 (Hall 1999). The combined data matrix contained 3010 characters; viz. 493 nucleotides of ITS, 1327 nucleotides of the LSU, 846 nucleotides of RPB2 and 344 nucleotides of TUB2.

Maximum parsimony (MP) analyses were performed with PAUP v. 4.0a166 (Swofford 2002). All molecular characters were unordered and given equal weight; analyses were performed with gaps treated as missing data; the COLLAPSE command was set to MINBRLEN. MP analysis of the combined multi-locus matrix was done using 1000 replicates of heuristic search with random addition of sequences and subsequent TBR branch swapping (MULTREES option in effect, steepest descent option not in effect). Bootstrap analyses with 1000 replicates were performed in the same way, but using 5 rounds of random sequence addition and subsequent branch swapping during each bootstrap replicate.

Maximum likelihood (ML) analyses were performed with RAxML (Stamatakis 2006) as implemented in raxmlGUI 1.3 (Silvestro and Michalak 2012), using the ML + rapid bootstrap setting and the GTRGAMMA substitution model with 1000 bootstrap replicates. The matrix was partitioned for the different gene regions. In the "Results" and "Discussion" sections, bootstrap values below $70 \%$ are considered low, between 70 and $90 \%$ medium and above $90 \%$ high.

\section{Pathogenicity}

Pathogenicity tests with the three fungal strains of the undescribed hazelnut pathogen were performed to fulfil Koch's postulates. For this, conidial suspensions were prepared by washing the conidia from actively sporulating agar cultures with sterile distilled water; the conidial concentration was determined using a haemocytometer, and the concentration adjusted with sterile distilled water to $1 \times 10^{6}$ conidia $/ \mathrm{ml}$. The isolates were tested either by inoculating the apex of fresh and mature hazelnuts after making a little hole with a sterile needle and introducing $25 \mu \mathrm{l}$ of conidial suspension into each kernel cavity (Scarpari et al. 2018) or a drop $(10 \mu \mathrm{l})$ of conidial suspension was adjusted at the centre of halved hazelnut kernels. The inoculated nuts (twenty replicates for each isolate) and negative controls (ten replicates) treated with sterile water only were all incubated in the dark at $25^{\circ} \mathrm{C}$ in a humid growth chamber for the first $72 \mathrm{~h}$. After 2 weeks, the results of inoculations were checked by halving the whole nuts or directly on the halved kernels.

\section{Results}

\section{Isolations and morphological characterization}

In the recent surveys carried out from 2016 to 2019, the undescribed fungal species associated with hazelnut fructifications was only isolated in Campania, during the whole vegetative season (from March to September) and occasionally from post-harvest nuts. Until now, the novel Corylus fungus has never been isolated in Piedmont. In the previous investigations of 2000-2010, colonies of this fungus were obtained in surveys conducted on hazelnut orchards in Viterbo province (Latium Region).

Culture images of three strains (CREADC-F2281, CREADC-F2402, CREADC-F2403) grown on OA, PDA, CMD and HEA for 2 weeks at room temperature are shown in Fig. 1. Detailed descriptions of morphological traits are given in the "Taxonomy" section below.

\section{Temperature-growth relationships}

The growth rate experiments (Fig. 2) revealed $20{ }^{\circ} \mathrm{C}$ as optimal temperature for all the three isolates with an evidently better growth of culture CREADC-F2281 (10.54 $\pm 0.25 \mathrm{~mm} /$ day), originating from Latium region, compared to the exholotype culture CREADC-F2403 with $7.50 \pm 1.07 \mathrm{~mm} /$ day. Conversely, the ex-holotype culture showed a faster growth at $25{ }^{\circ} \mathrm{C}$ in comparison with the other two isolates. No growth was recorded at $35^{\circ} \mathrm{C}$, while all three isolates were able to grow at $5^{\circ} \mathrm{C}$, at which the ex-holotype culture performed best $(1.55 \pm 0.1 \mathrm{~mm} /$ day $)$.

\section{Phylogenetic analyses}

Of the 3010 characters included in the phylogenetic analyses, 449 were parsimony informative (41 from the ITS, 20 from the LSU, 256 from RPB2, 132 from TUB2). MP analyses revealed 114 MP trees 2199 steps long, one of which is shown as Fig. 3. The tree backbone was identical in all MP trees, except for topologies of several deeper nodes of the Peyronellaea clade marked by an asterisk in Fig. 3. The best ML tree $(\operatorname{lnL}=-14,674.1908)$ revealed by RAxML was largely compatible with the MP tree shown in Fig. 3, except for differences in some deeper unsupported nodes (not shown). In the MP and ML analyses, the novel Corylus fungus was placed within a clade containing D. pedeiae, D. ilicicola and D. subherbarum with maximum support (group G of Aveskamp et al. 2010), but it remained unresolved whether D. ilicicola or D. subherbarum is its closest relative (Fig. 3).

\section{Pathogenicity}

Necrotic lesions were evident on the halved kernels while rather limited on the whole nuts. Re-isolations from the margin of lesions cultured on PDA gave colonies with the same morphological characters as those used for inoculation, thus confirming Koch's postulates. 
Fig. 1 Didymella corylicola cultures after 14 days at $22{ }^{\circ} \mathrm{C}$ on $\mathrm{OA}(\mathbf{a}-\mathbf{c}), \operatorname{PDA}(\mathbf{d}-\mathbf{f}), \mathrm{CMD}(\mathbf{g}-\mathbf{i})$ and HEA $(\mathbf{j}-\mathbf{l})$. $\mathbf{a}, \mathbf{d}, \mathbf{g}, \mathbf{j}$ Strain CREADC-F2402. b, e, h, k Strain CBS $146357=$ CREADC-F2403 (ex-holotype). c, f, i, I Strain CREADC-F2281
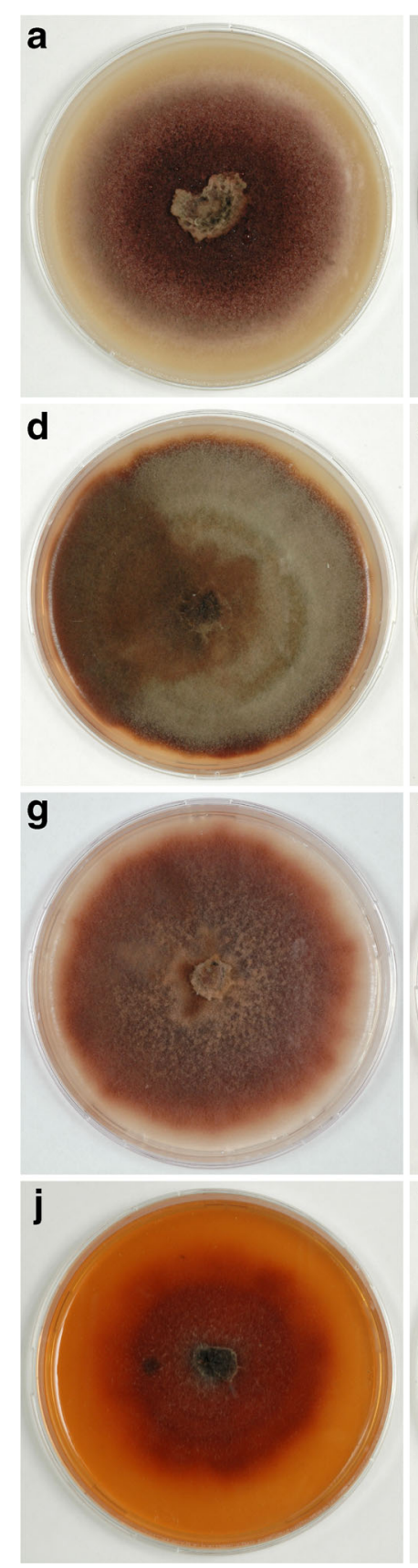
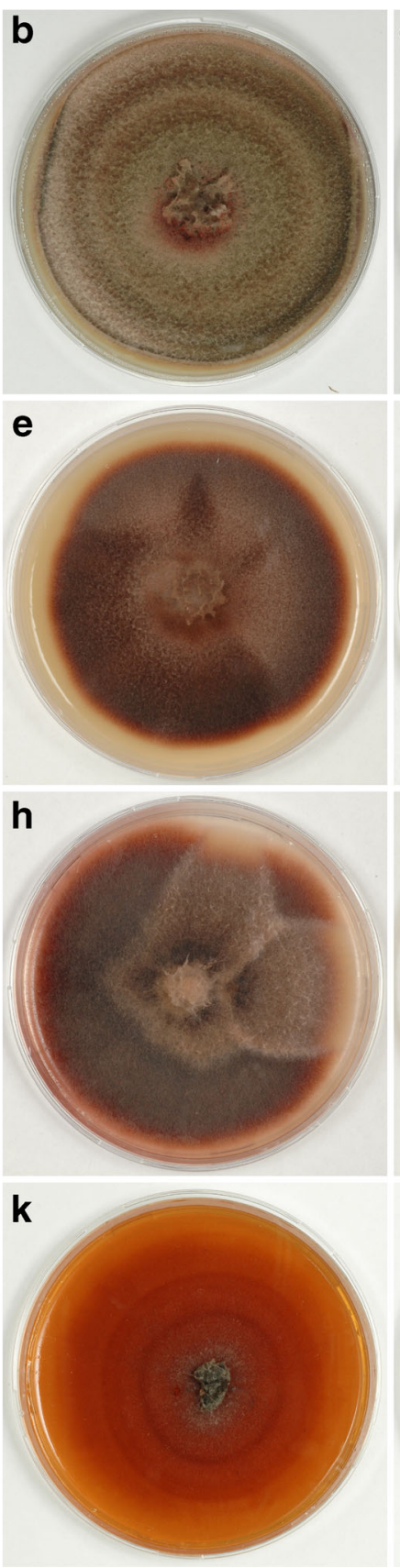
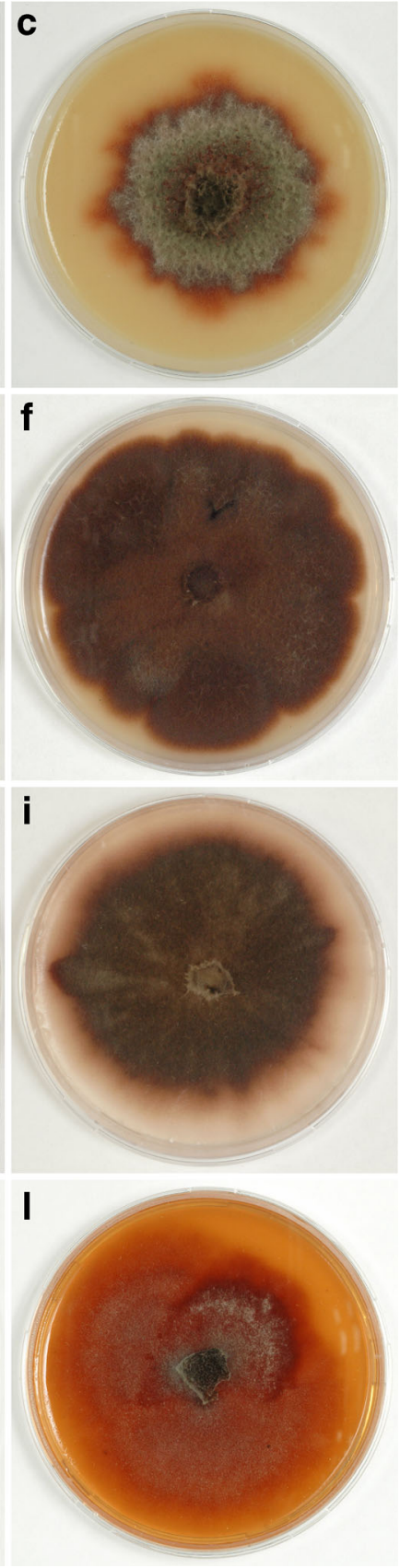

\section{Taxonomy}

Didymella corylicola Voglmayr, Scarpari, Di Giambattista, Vitale and Luongo sp. nov. Figs 1 and 4.

MycoBank: MB 833929

Etymology: corylicola, referring to its occurrence on Corylus fructifications.

Diagnosis: Didymella corylicola is recognized by colonies producing bright red diffusible pigments in pure culture.

Description: Pycnidia (46-)55-82(-110) $\mu \mathrm{m}$ diameter $(n=100)$, solitary, produced within the agar, on the agar surface or on the aerial mycelium, (sub-)globose to broadly pyriform, glabrous, brown, with 1 (rarely 2 ) conspicuous, non-papillate ostioles $(8-) 11-17(-22) \mu \mathrm{m}$ wide $(n=32)$. Pycnidial wall (4-)4.5-6.5(-7.5) $\mu \mathrm{m}$ thick $(n=31)$, brown, pseudoparenchymatous, composed of 1-3 layers of isodiametric to oblong cells $(4-) 6-10(-16) \times(3-) 4-8(-11) \mu \mathrm{m}$ $(n=66)$. Conidiogenous cells $(4.3-) 4.5-7.8(-$ $10.0) \times(2.8-) 3.5-5.0(-5.8) \mu \mathrm{m}(n=18)$, phialidic, hyaline, simple, smooth, globose to flask-shaped. Conidia (3.2-)3.8$4.5(-5.3) \times(1.4-) 1.6-1.9(-2.1) \mu \mathrm{m}, 1 / \mathrm{w}=(1.7-) 2.1-2.6(-$ 3.1) $(n=221)$, ellipsoidal to oblong, commonly slightly allantoid, thin-walled, smooth, hyaline, aseptate, with 0 2 tiny guttules. Conidial matrix white. 
Fig. 2 Temperature-growth relationships of the ex-holotype strain CBS $146357=$ CREADCF2403 compared to two other strains of Didymella corylicola on PDA. Daily mean growth rate $(\mathrm{mm} /$ day $) \pm \mathrm{SD}$ calculated on three replicates after 7 days of incubation are shown

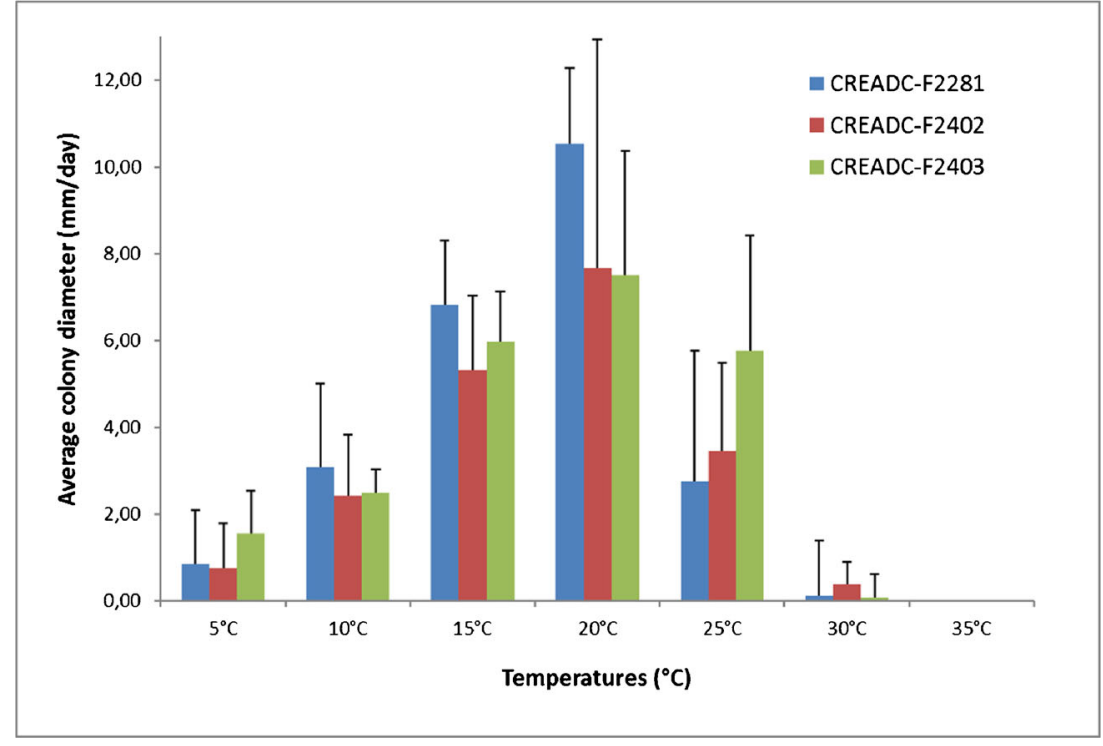

Culture characteristics: Colonies on PDA 47-62 mm diameter after 7 days at $22{ }^{\circ} \mathrm{C}$, margin regular or irregular, covered by floccose aerial mycelium, grey brown to dark vinaceous brown, at least in the centre becoming dark vinaceous brown with age, sometimes with concentric rings; reverse blackish with bright red brown margins. Colonies on MEA 53-58 mm diameter after 7 days at $22{ }^{\circ} \mathrm{C}$, with culture characteristics similar to those on PDA. Colonies on CMD 67$72 \mathrm{~mm}$ diameter after 7 days at $22^{\circ} \mathrm{C}$, with culture characteristics similar to those on PDA. Colonies on OA with regular or irregular margin, covered by floccose aerial mycelium, olivaceous brown, grey brown to dark vinaceous brown, at least in the centre becoming dark vinaceous brown with age, sometimes with concentric rings; reverse buff to olivaceous brown with a dark vinaceous brown centre. Colonies on HEA with sparse aerial mycelium, bright orange red, becoming dark carmine red in the centre, sometimes with darker concentric rings, producing diffusible pigments staining the agar bright orange; reverse orange red to dark carmine red. Immersed hyphae with age containing rosy to carmine red pigments in all media tested. $\mathrm{NaOH}$ test negative.

Holotype: Italy, Campania region, Caserta province, Teano, from kernel of Corylus avellana (Betulaceae) at harvest phase, August 2017 (WU 40039; ex-holotype culture CBS 146357 = CREADC-F2403).

Other specimens examined (all from kernels of Corylus avellana): Italy, Campania, Caserta province, Teano, August 2017 (WU 40040, culture CREADC-F2402); Latium, Viterbo province, Ronciglione, August 2006 (WU 40041, culture CREADC-F2281).

Notes: Didymella corylicola is phylogenetically closely related to D. pedeiae, D. ilicicola and D. subherbarum (Fig. 3), from which it differs in 1, 1 and 2 nucleotides, respectively, in the ITS; in 25, 3 and ? (no sequence available for $D$. subherbarum) nucleotides, respectively, in $R P B 2$; and in 14
15, 6-7 and 11-12 nucleotides, respectively, in TUB2. However, D. corylicola differs significantly from D. pedeiae, D. ilicicola and D. subherbarum in its bright red pigment produced in agar cultures and by its specific host, Corylus avellana. Morphologically, D. corylicola has conidial sizes similar to those of D. ilicicola, D. pedeiae and $D$. subherbarum $(D$. corylicola: $3.2-5.3 \times 1.4-2.1 \mu \mathrm{m} ; D$. ilicicola: $3-4 \times 1.5-2.5 \mu \mathrm{m}$ (Chen et al. 2017); D. pedeiae $3-4.5 \times 1.5-2.5 \mu \mathrm{m}$ (Aveskamp et al. 2010); $D$. subherbarum: $4-6.4 \times 1.6-2.2 \mu \mathrm{m}$ (de Gruyter et al. 1993)). However, in contrast to its closest relatives which all have straight ellipsoid to oblong conidia, the conidia of D. corylicola are commonly slightly allantoid.

\section{Discussion}

The Didymellaceae in general and the genus Didymella in particular are a species-rich lineage within Pleosporales, containing numerous plant pathogens (Chen et al. 2015, 2017). The taxonomy of the group is complex and challenging, as it contains, amongst others, highly speciose sexual (Didymella, Ascochyta) as well as asexual (e.g. Epicoccum, Phoma) morph genera. Until recently, the simple morphology of both sexual and asexual morphs was a serious obstacle for reliable genus and species circumscriptions as well as for species identification. However, with the application of multigene phylogenies, substantial progress in genus and species delimitation

Fig. 3 Phylogram showing one of 114 MP trees 2199 steps long revealed by PAUP from an analysis of the combined ITS-LSU-RPB2-TUB2 matrix of Didymella, showing the phylogenetic position of D. corylicola (bold red). MP and ML bootstrap support above $50 \%$ are given above or below the branches. Nodes marked by an asterisk (*) collapsed in the strict consensus of all 114 MP trees. The ex-holotype strain of D. corylicola is marked by a superscript HT. 


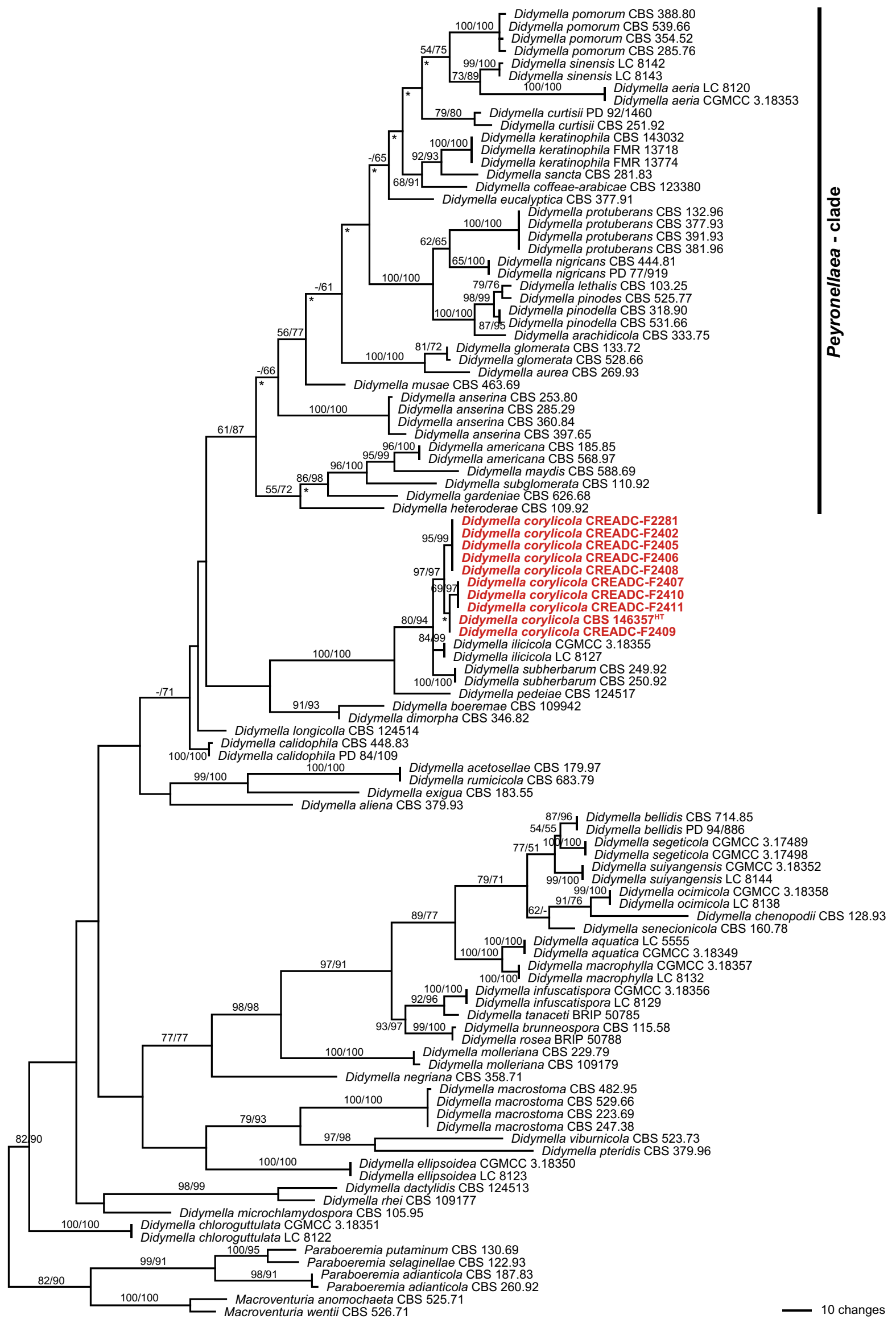




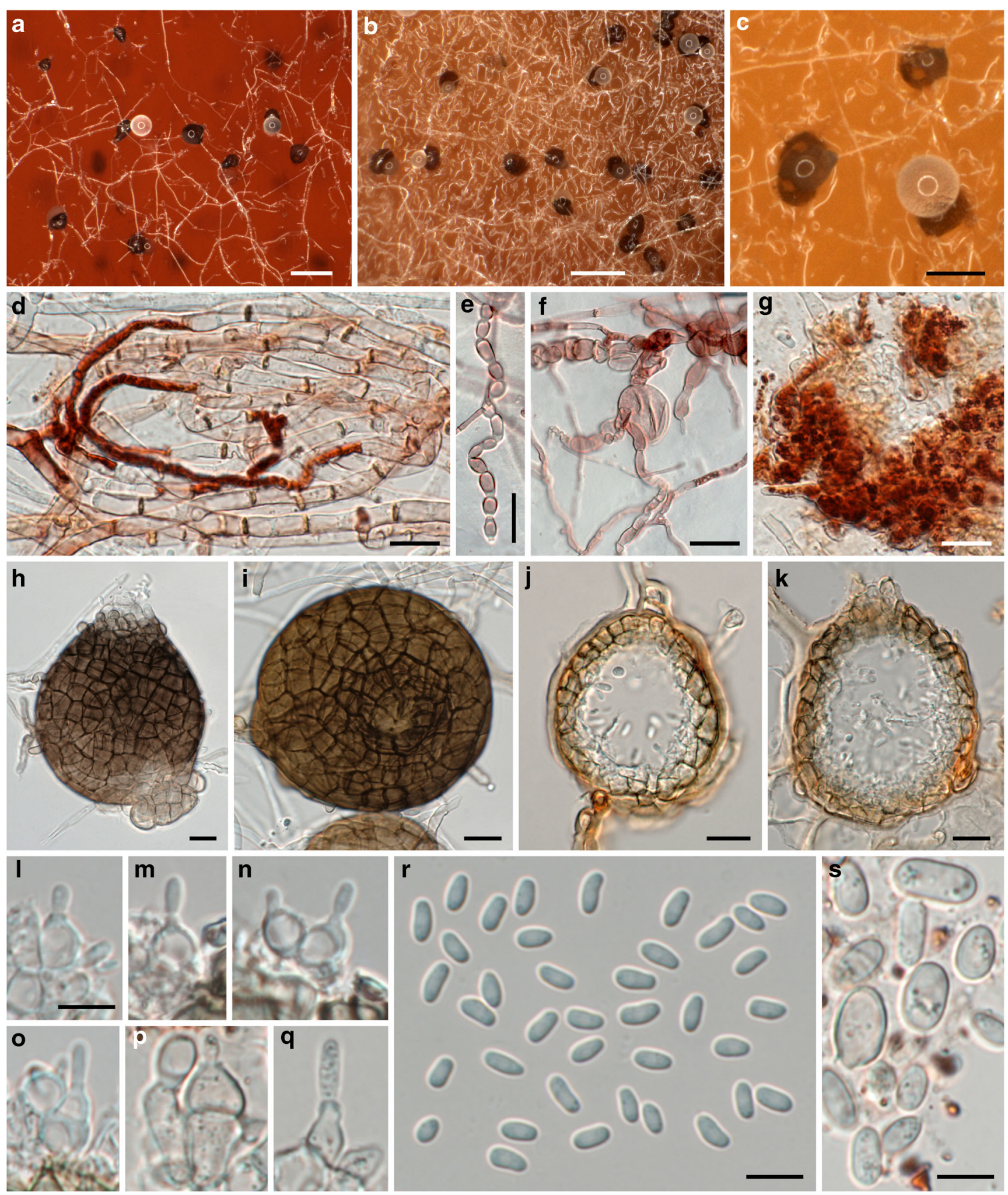

Fig. 4 Didymella corylicola. a-c Pycnidia in face view. d Substrate hyphae. e, $\mathbf{f}$ Torulose hyphae. $\mathbf{g}$ Amorphous red pigments in agar. h, $\mathbf{i}$ Pycnidia in side (h) and face (i) view. $\mathbf{j}, \mathbf{k}$ Pycnidia in section. $\mathbf{l}-\mathbf{q}$ Conidiogenous cells (phialides). r, s Conidia (s ejected and swollen, with amorphous red pigments in-between). All in water, except $\mathbf{h}, \mathbf{i}$ in
3\% KOH. Media: a HEA; b-d, g-s HTA; e, f MEA. Sources: a-c, e, f, ho, r ex-holotype strain CBS $146357=$ CREADC-F2403; d, g, p, q, s CREADC-F2402. Scale bars a, b $200 \mu \mathrm{m} ; \mathbf{c} 100 \mu \mathrm{m} ; \mathbf{d}-\mathbf{k} 10 \mu \mathrm{m} ; \mathbf{l}-\mathbf{s}$ $5 \mu \mathrm{m}$ 
within Didymellaceae has been achieved in recent years (Aveskamp et al. 2010; Chen et al. 2015, 2017), in particular for the large genera Ascochyta, Didymella and Phoma. Several new genera were established, the genus Phoma was restricted to the type species, $P$. herbarum, and numerous species of Phoma were transferred to the genera Allophoma, Ascochyta, Boeremia, Calophoma, Didymella, Epicoccum, Heterophoma, Neoascochyta, Neodidymelliopsis, Nothophoma, Paraboeremia, Stagonosporopsis and Xenodidymella (Chen et al. 2015). In addition, new species of Didymella have been described (e.g. Chen et al. 2015, 2017; Valenzuela-Lopez et al. 2018), highlighting that the species diversity of Didymella is still insufficiently known.

In the molecular phylogenetic analyses, $D$. corylicola forms a highly supported clade with $D$. pedeiae, D. ilicicola and D. subherbarum, which corresponds to Phoma group G of Aveskamp et al. (2010). In contrast to D. corylicola, which is, as far known, host specific to Corylus, D. pedeiae and $D$. subherbarum are plurivorous (Aveskamp et al. 2010), while D. ilicicola is so far only known from seedlings of Ilex chinensis (Chen et al. 2017). All species of the clade share a negative $\mathrm{NaOH}$ reaction of the colonies, and while conidial sizes are overlapping with its closest relatives, $D$. corylicola is well characterised by the bright red pigment produced in agar cultures and its specific host. In addition, the genetic differences of $D$. corylicola justify its status as a distinct species.

Didymella corylicola represents a fungal species associated with hazelnut fructification from the primordial to postharvest phase. Its abundance in the early stages of fruit development may be facilitated by the psychrophilic nature of this fungus which is able to grow at $5{ }^{\circ} \mathrm{C}$. In addition, it seems to be associated only with hazelnut, since it has never been isolated from other common nut species such as walnut and pistachio, which were intensely surveyed in the past years by the authors (Belisario et al. 2002; Vitale et al. 2007, 2018; Scotton et al. 2015), and it has never been reported from almond. Although weak pathogenicity was revealed in the inoculation experiments, the impact of $D$. corylicola on the development of hazelnut fruit is yet unclear. Ongoing studies might show whether this fungus plays a direct role in the emergence of kernel defects, or whether it has an indirect effect by an interaction with known hazelnut fruit pathogens such as Colletotrichum spp., Diaporthe spp. or Fusarium spp.

Acknowledgements The research was carried out with the cooperation and contribution of the Hazelnut company division of Ferrero Group.

Funding Information Open access funding provided by University of Vienna.

Open Access This article is licensed under a Creative Commons Attribution 4.0 International License, which permits use, sharing, adaptation, distribution and reproduction in any medium or format, as long as you give appropriate credit to the original author(s) and the source, provide a link to the Creative Commons licence, and indicate if changes were made. The images or other third party material in this article are included in the article's Creative Commons licence, unless indicated otherwise in a credit line to the material. If material is not included in the article's Creative Commons licence and your intended use is not permitted by statutory regulation or exceeds the permitted use, you will need to obtain permission directly from the copyright holder. To view a copy of this licence, visit http://creativecommons.org/licenses/by/4.0/.

\section{References}

Aveskamp MM, Verkley GJ, de Gruyter J, Murace MA, Perelló A, Woudenberg JH, Groenewald JZ, Crous PW (2009) DNA phylogeny reveals polyphyly of Phoma section Peyronellaea and multiple taxonomic novelties. Mycologia 10:363-382

Aveskamp MM, de Gruyter J, Woudenberg JHC, Verkley GJM, Crous PW (2010) Highlights of the Didymellaceae: a polyphasic approach to characterise Phoma and related pleosporalean genera. Stud Mycol 65:1-60

Belisario A, Maccaroni M, Corazza L, Balmas V, Valier A (2002) Occurrence and etiology of brown apical necrosis on Persian (English) walnut fruit. Plant Dis 86:599-602

Chen Q, Hou LW, Duan WJ, Crous PW, Cai L (2017) Didymellaceae revisited. Stud Mycol 87:105-159

Chen Q, Jiang JR, Zhang GZ, Cai L, Crous PW (2015) Resolving the Phoma enigma. Stud Mycol 82:137-217

de Gruyter J, Noordeloos ME, Boerema GH (1993) Contributions towards a monograph of Phoma (Coelomycetes)-I. 2. Section Phoma: additional taxa with very small conidia and taxa with conidia up to $7 \mu \mathrm{m}$ long. Persoonia 15:369-400

de Hoog GS, Gerrits van den Ende AHG (1998) Molecular diagnostics of clinical strains of filamentous basidiomycetes. Mycoses 41:183-189

Enescu CM, Houston Durrant T, de Rigo D, Caudullo G (2016) Corylus avellana in Europe: distribution, habitat, usage and threats. In: SanMiguel-Ayanz J, de Rigo D, Caudullo G, Houston Durrant T, Mauri A (eds) European atlas of forest tree species. Publications Office of the European Union, Luxembourg, pp 86-87

Hall TA (1999) BioEdit: a user-friendly biological sequence alignment editor and analysis program for Windows 95/98/NT. Nucleic Acids Symp Ser 41:95-98

Librandi I, Galli M, Belisario A (2006) Le patologie del frutto del nocciolo in Italia, con particolare riguardo alla zona del viterbese. Petria 16:125-134

Liu YL, Whelen S, Hall BD (1999) Phylogenetic relationships among ascomycetes: evidence from an RNA polymerase II subunit. Mol Biol Evol 16:1799-1808

Minutolo M, Nanni B, Scala F, Alioto D (2016) Sphaceloma coryli: a reemerging pathogen causing heavy losses on hazelnut in southern Italy. Plant Dis 100:548-554

O’Donnell K, Cigelnik E (1997) Two divergent intragenomic rDNA ITS2 types within a monophyletic lineage of the fungus Fusarium are nonorthologous. Mol Phylogenet Evol 7:103-116

Olsen J (2013) Growing hazelnuts in the Pacific Northwest: introduction. Oregon State University extension fruit-nuts, EM 9072. Available at https://catalog.extension.oregonstate.edu/sites/catalog/files/ project/pdf/em9072.pdf

Scarpari M, Di Gianbattista G, Vitale S, Luongo L, De Gregorio T, Schreiber G, Belisario A (2018) First report of kernel dry rot caused by Eremothecium coryli on hazelnut in northwestern Italy. Plant Dis 102:2652

Scotton M, Bortolin E, Fiorin A, Belisario A (2015) Environmental and pathogenic factors inducing brown apical necrosis on fruit of English (Persian) walnut. Phytopathology 105:1427-1436 
Silvestro D, Michalak I (2012) raxmlGUI: a graphical front-end for RAxML. Org Divers Evol 12:335-337

Stamatakis E (2006) RAxML-VI-HPC: maximum likelihood-based phylogenetic analyses with thousands of taxa and mixed models. Bioinformatics 22:2688-2690

Sung GH, Sung JM, Hywel-Jones NL, Spatafora JW (2007) A multi-gene phylogeny of Clavicipitaceae (Ascomycota, fungi): identification of localized incongruence using a combinational bootstrap. Mol Phylogenet Evol 44:1204-1223

Swofford DL (2002) PAUP* 4.0b10: phylogenetic analysis using parsimony *and other methods. Sinauer associates, Sunderland

Valenzuela-Lopez N, Cano-Lira JF, Guarro J, Sutton DA, Wiederhold N, Crous PW, Stchigel AM (2018) Coelomycetous Dothideomycetes with emphasis on the families Cucurbitariaceae and Didymellaceae. Stud Mycol 90:1-69

Vilgalys R, Hester M (1990) Rapid genetic identification and mapping of enzymatically amplified ribosomal DNA from several Cryptococcus species. J Bacteriol 172:4238-4246

Vitale S, Aiello D, Guarnaccia V, Luongo L, Galli M, Crous PW, Polizzi G, Belisario A, Voglmayr H (2018) Liberomyces pistaciae sp. nov., the causal agent of pistachio cankers and decline in Italy. MycoKeys 40:29-51

Vitale S, Avanzato D, Belisario A (2007) Malattie fungine del pistacchio, possibile ostacolo allo sviluppo della coltivazione nell'Italia centrale. Riv Frutticoltura Ortofloricoltura 69(12):68-71

Vitale S, Santori A, Wajnberg E, Castagnone-Sereno P, Luongo L, Belisario A (2011) Morphological and molecular analysis of
Fusarium lateritium, the cause of gray necrosis of hazelnut fruit in Italy. Phytopathology 101:679-686

Voglmayr H, Jaklitsch WM (2008) Prosthecium species with Stegonsporium anamorphs on Acer. Mycol Res 112:885-905

Voglmayr H, Jaklitsch WM (2011) Molecular data reveal high host specificity in the phylogenetically isolated genus Massaria (Ascomycota, Massariaceae). Fungal Divers 46:133-170

Voglmayr H, Rossman AY, Castlebury LA, Jaklitsch WM (2012) Multigene phylogeny and taxonomy of the genus Melanconiella (Diaporthales). Fungal Divers 57:1-44

Voglmayr H, Akulov OY, Jaklitsch WM (2016) Reassessment of Allantonectria, phylogenetic position of Thyronectroidea, and Thyronectria caraganae sp. nov. Mycol Prog 5:921-937

Werle E, Schneider C, Renner M, Völker M, Fiehn W (1994) Convenient single-step, one tube purification of PCR products for direct sequencing. Nucleic Acids Res 22:4354-4355

White TJ, Bruns T, Lee S, Taylor J (1990) Amplified and direct sequencing of fungal ribosomal RNA genes for phylogenies. In: Innis MA, Gelfand DH, Sninsky JJ, White TJ (eds) PCR protocols: a guide to methods and applications. Academic Press, San Diego, pp 315-322

Publisher's note Springer Nature remains neutral with regard to jurisdictional claims in published maps and institutional affiliations. 